\title{
Effect of Ramadan fasting on metabolic markers, body composition, and dietary intake in Emiratis of Ajman (UAE) with metabolic syndrome
}

This article was published in the following Dove Press journal:

Diabetes, Metabolic Syndrome and Obesity:Targets and Therapy

14 December 2011

Number of times this article has been viewed

\author{
Amena Sadiya' \\ Solafa Ahmed' \\ Hisham Hussain Siddieg \\ Irish Joy Babas' \\ Martin Carlsson ${ }^{1,2}$ \\ 'Rashid Centre for Diabetes and \\ Research, Ministry of Health, Ajman, \\ UAE; ${ }^{2}$ Kalmar County Hospital, \\ Sweden
}

Background/aim: The aim of the study was to evaluate the effect of Ramadan fasting on metabolic markers, body composition and dietary intake in native Emiratis of Ajman, UAE with the metabolic syndrome (MS).

Design: 19 patients (14 Female, 5 Male) aged $37.1 \pm 12.5$ years, were encouraged healthy lifestyle changes during fasting and data was collected 1 week before and in the fourth week of Ramadan.

Results: No patients experienced complications or increased symptoms of hypoglycemia during Ramadan. Total energy consumption remained similar. Meal frequency decreased $(3.2 \pm 0.5$ vs $2.1 \pm 0.4$ meals/day $)$. Protein intake decreased $12 \%(P=0.04)$ but fat intake increased 23\% $(P=0.03)$. Body weight $(103.9 \pm 29.8$ vs $102.1 \pm 29.0 \mathrm{~kg}, P=0.001)$ and waist circumference $(123 \pm 14$ vs $119 \pm 17 \mathrm{~cm}, P=0.001)$ decreased. Forty percent of patients increased their physical activity due to increased praying hours. Fasting P-glucose $(6.3 \pm 1.7$ vs $6.8 \pm 2.0 \mathrm{mmol} / \mathrm{L}, P=0.024)$ and $\mathrm{B}-\mathrm{HbA}_{1 \mathrm{c}}$ concentrations $6.3 \pm 0.9$ vs $6.5 \% \pm 0.9 \%$, $P=0.003$ ) increased but $\mathrm{P}$-insulin concentration, HOMA-IR index and lipid concentrations remained unchanged.

Conclusion: The present study investigated the effect of Ramadan fasting on dietary intake, metabolic parameters and body composition showing that the energy consumption per day did not decrease, although the fat intake increased. However, the patients lost weight and reduced their waist circumference. Ramadan fasting has also elicited small but significant increases in Glucose and $\mathrm{HbA}_{1 \mathrm{c}}$ after 4 weeks.

Keywords: metabolic syndrome, Ramadan, fasting, body composition, type 2 diabetes, obesity, Ajman

\section{Introduction}

Ramadan is the holiest month in the Islamic calendar. Since it is a lunar-based month its duration varies between 29 and 30 days. Muslims fast everyday from dawn to sunset and refrain from drinking and eating for this period; however, there are no restrictions on food or fluid intake between sunset and dawn. The period of fast may vary depending on the geographical location of the country and the season of the year. ${ }^{1}$

The Ramadan model of fasting is abundantly available but not extensively studied and the physiological changes induced by Ramadan fasting are not well known. Although there have been reports on the metabolic changes during and after Ramadan in healthy subjects ${ }^{2,3}$ and in patients with diabetes ${ }^{4,5}$ the results have been conflicting. ${ }^{6,7}$ The variability in the results is probably attributed to several confounding variables like ethnicity, hours of fasting, climatic conditions, cultural influences, physical
Rashid Centre for Diabetes and Research, Ministry of Health, Ajman, UAE.

Tel +97l 67147345

Email sadiya.amena@gmail.com 
activity and most commonly the dietary patterns. ${ }^{6}$ Muslims with diabetes and other chronic diseases are exempted from fasting, when fasting may lead to harmful consequences. However, many patients insist on participating in Ramadan fasting. Because of the conflicting results regarding the effects of Ramadan fasting, physicians working in Muslim communities often face a difficult task when advising patients with diabetes or Metabolic Syndrome (MS) whether it is safe to fast, as well as recommending the proper dietary and drug regimens.

Food consumption patterns and dietary habits in the Arabian Gulf have changed in the recent past, due to increasing wealth and westernization. ${ }^{8}$ Obesity and type 2 diabetes mellitus (DM) have recently reached epidemic proportions in the region. The prevalence of the MS in the United Arab Emirates (UAE) is now reported to be one of the highest in the world reaching approximately $40 \%$ using the National Cholesterol Education Program (NCEP) definition or the International Diabetes Federation (IDF) definition. ${ }^{9}$

The high prevalence is possibly caused by genetic factors in combination with rapid socioeconomic developments. Many Emiratis have in the past 20-30 years adapted a sedentary lifestyle with a minimum of physical activity and an over consumption of energy-dense food..$^{10}$ Presence of MS serves well as a simple clinical tool for identifying highrisk subjects predisposed to cardiovascular disease. ${ }^{11}$ The dominant underlying risk factors for this syndrome appear to be abdominal obesity and insulin resistance. Prevention or reduction of obesity, particularly abdominal obesity, is a main therapeutic goal in patients with MS. ${ }^{12}$

Weight reduction can be optimally achieved with a multimodality approach by adapting to healthy lifestyle through diet modification, physical activity and possible pharmacological therapy. ${ }^{13}$ A moderate weight loss of about $5 \%$ has shown to improve glycemic and blood pressure control, improve insulin action, decrease fasting plasma glucose concentrations, as well as improve lipid

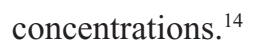

Based on the Ministry of Economy census in 2005, $76 \%$ of the total population is Muslim in the UAE, ${ }^{15}$ and most of the adult population adheres to the Ramadan fasting.

To the best of our knowledge, we are not aware of any previous published reports on the effect of Ramadan fasting on the subjects with the MS in this region. Therefore, the present pilot study was undertaken at Rashid Centre for Diabetes and Research (RCDR), Ajman, UAE to evaluate the effect of Ramadan fasting on the metabolic markers, body composition and dietary intake in the subjects with MS in Ajman, UAE.

\section{Materials and methods Subjects}

The subjects were randomly selected based on the inclusionexclusion criteria. Twenty-three subjects were recruited, four withdrew and 19 subjects (14 female and five male) aged $37.1 \pm 12.5$ years completed the study.

The inclusion criteria included UAE national (passport holder) and abiding to Ramadan fast with the MS. A participant was defined as having MS if three or more of the following criteria were met, according to the IDF recommendations: ${ }^{16}$ (1) Central obesity, ie, waist circumference $\geq 94 \mathrm{~cm}$ for men and $\geq 80 \mathrm{~cm}$ for women (criteria for Middle East (Arab) population); (2) Hypertriglyceridemia $\geq 150 \mathrm{mg} / \mathrm{dL}(1.7 \mathrm{mmol} / \mathrm{L})$; (3) Low HDL-cholesterol (HDL-C), ie, $<40 \mathrm{mg} / \mathrm{dL}(1.03 \mathrm{mmol} / \mathrm{L})$ in males and $<50 \mathrm{mg} / \mathrm{dL}(1.29 \mathrm{mmol} / \mathrm{L})$ in females; (4) Raised blood pressure: $\geq 130 / 85 \mathrm{mmHg}$; (5) Raised fasting plasma glucose (FPG): $\geq 100 \mathrm{mg} / \mathrm{dL}(5.6 \mathrm{mmol} / \mathrm{L})$.

Exclusion criteria included Type 1 diabetes, Type 2 diabetes for more than 5 years, Type 2 diabetes on insulin treatment, $\mathrm{HbA}_{1 \mathrm{c}}>10 \%$ (National Glycohemoglobin Standardization Program (NGSP) standard), history of repeated hypoglycemic episodes, pregnancy or acute and chronic diseases.

The study protocol was approved by the regional Ethical committee of Ministry of health, UAE and the purpose of the research was explained to the participants and written consent was obtained. The patients stated that they had not changed any medication in the last 3 months or suffered with any acute disease or infection in the preceding 2 weeks prior to the study.

All the subjects were advised to recognize warning symptoms of dehydration, hypoglycemia and other possible complications and were encouraged healthy lifestyle changes during Ramadan fasting.

The data was collected via structured interview supported by a questionnaire; the objective of the interview was to gather socio-demographic data, current treatment, lifestyle changes during fasting, days of fasting, sleeping hours, frequency of hypoglycemia and compliance to the dietary instructions.

Data collected included (1) sociodemographic data, diabetes type, duration of the disease, complications, and comorbidities; (2) current treatment, frequency, and type of medical follow-up (self-monitoring and monitoring of 
glycemia); (3) physical activity, food/fluid intake, sleep patterns, and body weight; and (4) consequences of the Ramadan period with regards to change in lifestyle, change in treatment, and change in frequency of hypo/hyperglycemia episodes. The methodology of the study and recommendations on how to conduct the interviews and complete the questionnaires were presented to each investigator during briefing meetings by representatives of the study. An identical questionnaire was translated into the local language.

The data was collected 1 week before Ramadan (RA1) and in fourth week of Ramadan (29th and 30th of Ramadan) (RA2). The climate in the region during Ramadan was hot and dry and the average minimum and maximum temperature was $29.7^{\circ} \mathrm{C}$ and $44.7^{\circ} \mathrm{C}$ respectively throughout the month.

\section{Anthropometric measurements}

The body weight and height were measured by the same person using an electronic balance with stadiometer (SECA-Germany, capacity: $\max 250 \mathrm{~kg}$, range: $110 \mathrm{~cm} / 43$ ins, $200 \mathrm{~cm} / 79$ ins) and recorded to the nearest $0.1 \mathrm{~kg}$ and $0.1 \mathrm{~cm}$ respectively. The body composition was determined by bioelectric impedance using InBody-230 (Biospace, Dogok-dong, South Korea) to study the fat mass (FM), muscle mass (MM) and total body water (TBW). The analysis was performed each time under standardized conditions ie, 2 hours fasting and no intense physical exercise 12 hours prior to the test and in fourth week of Ramadan before midday, no menstrual cycle and \pm 2 days The body mass index (BMI) (calculated as weight $(\mathrm{kg}) /$ height $^{2}$ $\left.\left(\mathrm{m}^{2}\right)\right)$ was also estimated.

Basal metabolic rate (BMR) indicates the minimum energy requirements needed to sustain vital functions while at rest. The InBody 230 makes it possible to estimate BMR using a known regression equation based on Fat Free Mass (FFM), a generalized prediction equation is proposed as $\mathrm{BMR}=370+21.6(\mathrm{FFM}) \cdot{ }^{17}$

The waist circumference (WC) was defined as the abdominal circumference immediately above the iliac crest and the hip circumference was measured in a horizontal plane at the level of the maximal extension of the buttocks according to the National Health and Nutrition Examination Survey (NHANES) guidelines. ${ }^{18}$

Systolic and diastolic blood pressure was measured in the right arms and in the sitting position of the subjects who had been resting for at least $10 \mathrm{~min}$.

\section{Dietary intake}

The dietary compliance was measured using a visual analog scale $^{19}$ and the nutrient intake was evaluated by means of a 3 day food record. The patients were instructed on how to record their daily dietary intake for 3 consecutive days; two weekdays and one weekend day. ${ }^{20}$ Food quantities were explained using household measurements (plates, glass, slice, cups, spoons, etc) and a sample food record was given for easy understanding. Then individual records were reviewed, and the nutrient calculations were carried out using the USDA's food composition table. ${ }^{21}$

\section{Biochemical assays}

The blood samples were collected after 8-10 hours of fasting, and processed for fasting plasma glucose using (Enzymatic

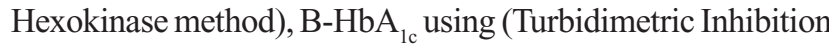
Immunoassay TINIA), plasma Insulin and C-peptide using (electrochemiluminescence Sandwich Assay). Plasma lipids (Cholesterol and Triglyceride, HDL and LDL-Cholesterol) were analyzed using enzymatic methods. The plasma apolipoproteins were analysed using immunoturbidimetric assay.

Liver function tests including ALP using (standardized method), AST using (rate assay without pyrodoxial phosphate activation method), ALT using (Colorimetric without pyrodoxial phosphate activation method), GGT using (enzymatic colorimetric method).

Plasma creatinine was analyzed using (kinetic colorimetric Jaffes method and enzymatic colorimetric method), Urea using (kinetic colorimetric assay), and CRP using (enhanced immunoturbidimetric assay).

All the above mention tests were performed in a Roche COBAS 6000 analyzer. ${ }^{22}$

We used a homeostasis model assessment for insulin resistance (HOMA-IR). The formula used to calculate HOMA-IR was $^{23}=($ glucose $(\mathrm{mmol} / \mathrm{l}) \times$ insulin $) / 22.5$.

\section{Statistical analysis}

The analyses were performed with STATISTICA (version 8, StatSoft $^{\circledR}$, Tulsa, USA).

The results are reported as mean values and standard deviations, group means before and after Ramadan was compared using Wilcoxon matched pair test. A $P$-value of less than 0.05 was considered as statistically significant.

\section{Results}

\section{Fasting and meal frequency}

The average number of fasting days was 26.2 (range 23-29; SD 2.0) and the average hours of fasting were 14 hours and $20 \pm 10$ minutes. Since Islamic rules do not permit females to fast during the menstrual period, all the females in the study missed $4 \pm 2$ days of fasting. As the subjects were fasting 
from sunrise to sunset the meal frequency decreased from $3.2 \pm 0.5$ to $2.1 \pm 0.4$.

\section{Medication}

Eight subjects were on metformin as monotherapy for glucose lowering therapy. Three type 2 diabetes and two obese subjects were on antilipemic drugs (statins); and two other type 2 diabetes patients were on antihypertensive drugs (calcium-channel blockers). The frequency of taking medicines was enquired in the questionnaire to learn that $\mathrm{n}=9(64 \%)$ patients were taking their medications everyday whereas $n=2(14 \%)$ of the subjects often missed their medication during the fasting month.

\section{Metabolic complications and hypoglycemia}

No patients experienced severe hypo or hyperglycemia or any other acute metabolic complication during Ramadan but two patients had slight symptoms of hypoglycemia twice in the month of fasting. This frequency or severity of hypoglycemic event was similar to the non-fasting months. The total sleeping time remained comparable before and during Ramadan ( $8.8 \pm 0.8$ vs $8.4 \pm 0.6$ hours/day). However, during Ramadan there was delayed and shortened periods of sleep in the night, which is compensated by day time sleeping.

\section{Physical activity}

Seven subjects (37\%) reported to have reduced their physical activity during the month and four (21\%) subjects maintained the same physical activity; however eight (42\%) of them reported to have increased their activity due to the extended hours of praying after the sunset.

\section{Anthropometric measurements}

After 1 month of fasting (RA2), body weight, BMI and the WC decreased significantly compared to before Ramadan (RA1) (Table 1). This weight loss was reflected in the body composition, by a reduced FM, TBW and MM. However, this decrease was not significantly from any one component of the body composition. The systolic (129 \pm 19 vs $126 \pm 12 \mathrm{mmHg}$ ) and diastolic blood pressure (69 $\pm 10 \mathrm{vs}$ $70 \pm 11 \mathrm{mmHg}$ ) showed no significant changes during the month of fasting.

\section{Dietary intake}

Eight (42\%), seven (37\%) and four (21\%) subjects reported poor, average and good dietary compliance respectively.
Table I Anthropometric parameters I week before Ramadan (RAI) and in fourth week of Ramadan (RA2)

\begin{tabular}{lll}
\hline Parameter & Mean (SD) & \\
\cline { 2 - 3 } & RAI & RA2 \\
\hline Weight $(\mathrm{kg})$ & $103.9(29.8)$ & $102.1(29.0)^{*}$ \\
BMI $\left(\mathrm{kg} / \mathrm{m}^{2}\right)$ & $40.2(10.2)$ & $40.0(10.5)^{* *}$ \\
WC $(\mathrm{cm})$ & $123(14.0)$ & $119(17.0)^{*}$ \\
WHR & $0.98(0.10)$ & $0.95(0.1 \mathrm{I})$ \\
Fat mass $(\mathrm{kg})$ & $50.3(19.6)$ & $49.5(20.3)$ \\
Fat \% & $47.3(8.3)$ & $46.9(8.2)$ \\
TBW $(\mathrm{kg})$ & $39.5(9.6)$ & $38.7(7.9)$ \\
TBW $(\%)$ & $38.8(5.8)$ & $39.0(5.8)$ \\
Fat free mass $(\mathrm{kg})$ & $53.5(13.0)$ & $52.6(10.6)$ \\
Fat free mass $(\%)$ & $52.7(8.3)$ & $53.1(8.2)$ \\
Muscle mass $(\mathrm{kg})$ & $14.1(3.5)$ & $13.9(2.7)$ \\
Muscle mass $(\%)$ & $13.9(2.5)$ & $14.1(2.4)$ \\
BMR (kcal) & $\mathrm{I}, 500(300)$ & $1,400(400)$ \\
\hline
\end{tabular}

Notes: Data are expressed as mean (standard deviation). $* P<0.01$; **P $<0.05$. Abbreviations: BMI, body mass index; WC, waist circumference; WHR, waistto-hip ratio; TBW, total body water; BMR, basal metabolic rate.

Mean daily energy and macronutrient intake of the subjects before (RA1) and during (RA2) Ramadan fasting are shown in Table 2. The total energy consumption per day did not change during Ramadan when compared to before Ramadan.

During Ramadan there was a decrease in the protein intake and an increase in fat intake. There was a nonsignificant trend towards reduced carbohydrate intake.

Table 2 shows the distribution of calories into different food groups before (RA1) and during (RA2) Ramadan fasting. The intake of different food groups is represented in Table 3.

\section{Biochemical parameters}

Table 4 shows the results of plasma biochemical variables before (RA1) and during (RA2) Ramadan fasting.

Table 2 Energy and Macronutrient intake of patients I week before Ramadan (RAI) and in fourth week of Ramadan (RA2)

\begin{tabular}{llll}
\hline Nutrient & \multicolumn{2}{l}{ Mean (SD) } & $\begin{array}{l}\text { Dietary } \\
\text { recommendation } \\
\text { (ADA) }\end{array}$ \\
\cline { 2 - 4 } & RA I & RA2 & $2000 \mathrm{kcal}$ \\
\hline Total calorie (kcal) & $2,240(700)$ & $2,300(600)$ & \\
Carbohydrate (g) & $264(94)$ & $249(65)$ & \\
Carbohydrate (\%) & $46.4(5.5)$ & $43.5(4.9)$ & $45 \%-65 \%$ \\
Protein (g) & $78.0(24.7)$ & $68.7(23.9)^{*}$ & \\
Protein (\%) & $14.4(3.0)$ & $12.0(2.3)^{*}$ & $15 \%-20 \%$ \\
Fat (g) & $85.0(28.3)$ & $104.0(31.8)^{*}$ & \\
Fat (\%) & $34.6(4.8)$ & $40.5(5.5)^{*}$ & $<25 \%$ \\
\hline
\end{tabular}

Notes: ADA = American Diabetes Association, 2004 recommendations (34, 35). $* P<0.05$ 
Table 3 Dietary intake of different food groups in patients I week before Ramadan (RAI) and in fourth week of Ramadan (RA2)

\begin{tabular}{|c|c|c|c|c|}
\hline \multirow[t]{2}{*}{$\begin{array}{l}\text { Food Group } \\
\text { serving }\end{array}$} & \multicolumn{2}{|c|}{$\begin{array}{l}\text { No of servings } \\
\text { mean (SD) }\end{array}$} & \multicolumn{2}{|c|}{$\begin{array}{l}\% \text { of total } \\
\text { calorie }\end{array}$} \\
\hline & RAI & RA2 & RAI & RA2 \\
\hline Cereals & $10.1(4.4)$ & 9.1 (3.7) & 36.1 & 31.7 \\
\hline Legumes & $0.2(0.4)$ & $0.1(0.3)$ & 0.4 & 0.2 \\
\hline Fruits & $3.4(2.1)$ & $2.2(1.5)$ & 7.2 & 5.4 \\
\hline Vegetables (raw) & $0.8(0.8)$ & $0.4(0.5)$ & 0.8 & 0.4 \\
\hline $\begin{array}{l}\text { Vegetables } \\
\text { (cooked) }\end{array}$ & $0.6(0.5)$ & I.I $(0.7)^{*}$ & 0.6 & I.I \\
\hline Low fat milk & $0.5(0.6)$ & $0.2(0.3)$ & 1.4 & 0.6 \\
\hline Whole milk & 2.4 (I.9) & $1.6(0.9)$ & 16.1 & 10.4 \\
\hline Lean meat & $3.9(2.7)$ & $2.9(2.2)$ & 7.0 & 5.4 \\
\hline Medium fat meat & $1.5(1.8)$ & $1.6(2.9)$ & 4.0 & 4.0 \\
\hline High fat meat & $0.0(0.0)$ & $0.8(\mathrm{I} .8)$ & 0.0 & 2.8 \\
\hline Fat & $10.3(3.6)$ & I $4.2(4.4)^{*}$ & 20.6 & 27.7 \\
\hline Nuts & $0.2(0.4)$ & $0.9(1.4)$ & 0.2 & 1.3 \\
\hline Sugar & $6.7(5.2)$ & $10.5(8.1)$ & 5.6 & 9.1 \\
\hline
\end{tabular}

Note: $* p<0.01$.

We found an increase in fasting plasma glucose and $\mathrm{HbA}_{1 \mathrm{c}}$ levels but these changes were not paralleled by any significant changes in markers for insulin resistance such as fasting plasma insulin and HOMA-IR index. Lipids,

Table 4 Biochemical parameters based on fasting blood samples in patients I week before Ramadan (RAI) and in fourth week of Ramadan (RA2)

\begin{tabular}{|c|c|c|}
\hline \multirow[t]{2}{*}{ Biochemical parameter } & \multicolumn{2}{|l|}{ Mean (SD) } \\
\hline & RAI & RA2 \\
\hline P-glucose (mmol/L) & $6.3(1.7)$ & $6.8(2.0)^{* *}$ \\
\hline $\mathrm{B}-\mathrm{Hb} \mathrm{A}_{\mathrm{Ic}} \%$ & $6.3(0.9)$ & $6.5(0.9)^{*}$ \\
\hline P-insulin (IU/mL) & $27.8(16.7)$ & $26.5(19.1)$ \\
\hline HOMA IR & $7.8(5.0)$ & $8.1(5.9)$ \\
\hline P-cholesterol (mmol/L) & $4.6(1.0)$ & $4.5(1.0)$ \\
\hline P-triglycerides (mmol/L) & $1.65(0.99)$ & $1.45(0.68)$ \\
\hline P-HDL-cholesterol ( $\mathrm{mmol} / \mathrm{L})$ & $\mathrm{I} .15(0.21)$ & $1.16(0.29)$ \\
\hline P-LDL-cholesterol (mmol/L) & $2.67(0.76)$ & $2.57(0.83)$ \\
\hline P-CRP (mg/L) & $10.6(9.8)$ & $10.1(14.2)$ \\
\hline P-Apo-AI (g/L) & $1.32(0.21)$ & $1.30(0.25)$ \\
\hline P-Apo-B (g/L) & $0.79(0.19)$ & $0.74(0.21)$ \\
\hline APOB/APOA ratio & $0.6 \mathrm{I}(0.17)$ & $0.59(0.18)$ \\
\hline P-AST (IU/L) & $21.1(6.6)$ & $19.0(5.5)$ \\
\hline P-ALT (IU/L) & $30.5(17.4)$ & $27.2(15.4)$ \\
\hline P-ALP (IU/L) & $78.4(21.5)$ & $78.5(21.9)$ \\
\hline P-GGt (IU/L) & $25.2(12.1)$ & $20.9(9.6)^{* *}$ \\
\hline P-creatinine (mmol/L) & $57.5(15.1)$ & $59.0(15.4)$ \\
\hline P-urea mmol/L & $3.73(0.97)$ & $3.82(1.10)$ \\
\hline
\end{tabular}

Notes: $* P<0.01 ; * * p<0.05$.

Abbreviations: $\mathrm{HbA}_{\mathrm{Ic}}$, glycosylated haemoglobin; HOMA, homeostatic model assessment of insulin resistance; CRP, C reactive protein; AST, aspartate aminotransferase; ALT, Alanine transaminase; ALP, Alkaline phosphatase; GGt, Gamma-glutamyltransferase. apolipoproteins, and CRP concentrations as well as kidney function tests such as plasma creatinine and urea concentrations remained unchanged. Liver function tests such as AST, ALT and ALP were unchanged during the study but GGt decreased slightly $(P=0.02)$.

\section{Discussion}

We wanted to study the impact of Ramadan fasting on food intake, metabolic parameters and anthropometry in native Emiratis in Ajman, UAE since we have found none or very limited previous information available from this region investigating the effect of Ramadan fasting in patients with the MS.

Strict compliance to healthy dietary modifications is a cornerstone in diabetes and obesity management. During Ramadan, the meal pattern and fluid intake is markedly altered and there are delayed and shortened periods of sleep. It would be possible that these changes in meal and sleeping rhythm could lead to an undesirable change in metabolism. We found a slight but significant increase in fasting plasma glucose and $\mathrm{HbA}_{1 \mathrm{c}}$ levels during Ramadan compared with before fasting. It is possible that the changes in sleep schedule and habits during Ramadan induce changes in the rhythmic pattern of a number of hormonal variables including cortisol which has an unfavorable influence on the glucose tolerance. It has also been argued that a given nutrient ingested at an unusual time can induce different metabolic effects. ${ }^{24}$ Previous research has shown that, unlike in non-fasting periods, cortisol concentrations are biphasic during Ramadan fasting. These researchers reported an increase in serum cortisol starting at $1200 \mathrm{~h}$ that reached a plateau between 1600 and $2000 .^{25}$ The altered sleep-wakefulness cycle could possibly also lead to changes in levels of the appetite regulating hormones leptin, neuropeptide-Y and insulin that play important roles in the long-term regulation of energy intake and expenditure. ${ }^{26}$ Unfortunately data on these hormones were not available in the current study.

Interestingly, the increased glucose and $\mathrm{HbA}_{1 \mathrm{c}}$ levels were not paralleled by an increased insulin resistance measured by HOMA IR or fasting insulin concentrations. Neither did we observe any differences in lipids, apolipoproteins nor in CRP levels before compared to during the fasting period.

During Ramadan there was a change in feeding pattern in which larger meals compensated for lower frequency of food ingestion. Therefore total energy intake during Ramadan did not differ compared with prior to the initiation of Ramadan. These findings negate the common belief that Muslims tend to overcompensate in terms of food intake during this fasting month. Similar results were reported earlier in UAE subjects ${ }^{27}$ 
while contradictory results were reported in Algerian and Indian Muslims. ${ }^{3,28}$ These discrepancies can probably be explained by the unique food habits in different countries.

Despite insignificant changes in the total energy intake, we detected a significant reduction in total weight, BMI and WC after 4 weeks of fasting. Similar results have been reported in normal subjects in Jordan ${ }^{25}$ while other studies have attributed the weight loss during Ramadan to lower calorie intake, ${ }^{1,2,27}$ however, these studies have not reported the changes in the body composition on weight loss.

We observed an insignificant trend in the body composition changes contributing to the weight loss in our study. It was reported that the weight loss was contributed largely from fat $(\mathrm{kg})$ followed by TBW $(\mathrm{kg})$ and to a lesser extent from muscle mass. It is possible that the weight loss, in part, could be attributed to efficient utilization of body fat during fasting $^{2}$ and largely from the abdominal fat since also the waist circumference was reduced significantly.

Shariatpanahi et $\mathrm{al}^{1}$ and Saleh et $\mathrm{al}^{29}$ reported similar reduction in waist circumference during Ramadan fasting among subjects with MS and healthy volunteers respectively. A reduced waist circumference usually correlates with improved insulin sensitivity, ${ }^{30}$ which we could not show in the present study. However, the number of participants in the study was limited and insulin resistance was measured by indirect methods (fasting insulin and HOMA IR) which could have influenced the result through reduced precision and statistic power. Liver function tests such as ALT and especially GGt have been shown to be biomarkers correlating with insulin resistance ${ }^{31}$ and central body fat. ${ }^{32}$

In the current study we observed a significant decrease in GGt and a nonsignificant trend towards lower AST and ALT levels during fasting which interestingly paralleled the decreased abdominal obesity in the patients.

Although the total energy intake was not altered significantly, the selection of food certainly changed in the month of Ramadan. In the UAE culture special festival foods that are richer in fats and sugars like thareed, harees, luqaimaat, sugary drinks (Vimto) are consumed in the fasting month.

On comparing the macronutrient consumption before and during Ramadan, we observed an increase in fat and decrease in protein intake, whereas the total carbohydrate remained comparable. However, the source of carbohydrate had shifted from complex carbohydrate (cereal, legume, fruit, vegetable) to more of simple sugars (sweets and sweetened drinks).
The observed increase in fat intake during Ramadan was in agreement to studies reported in other regions as well. $^{2-4,27}$ We also noted a small but significant decrease in protein intake $(2.4 \%)$, in contrast to what was reported in other studies. ${ }^{2,27}$

The consumption of carbohydrate and protein remained lower to the American Diabetic Association (ADA) recommendation, while the fat intake was higher ${ }^{33}$ (Table 2).

The increased intake of dietary fat during Ramadan exceeded the dietary recommendations and conventional therapy values for treating obesity $(25 \%-30 \%) .{ }^{34}$ Similar results have been reported in other studies in UAE, Tunisia, and Algeria. . $27,35^{-15}$

The intake of vegetables was far less (1.4-1.5 servings/day) than the ADA recommendations (4-5 servings/day); however, the intake of cooked vegetable was increased compared to Pre-Ramadan due to a traditional dish called thareed, which consisted of vegetables like zucchini, carrot, tomato and cauliflower.

The intake of whole fruit was reduced; however, the fruit intake (two servings per day) was largely contributed only by dates and fruit juice during Ramadan. The subjects also reduced the consumption of milk and milk products, and the lean meat options were replaced by medium fat and high fat meat preparations.

Although the intake of fat and simple sugars increased there was no impairment in plasma lipid profile. These results are in line with the study reported in normal UAE and Kuwaiti subjects. ${ }^{27,29}$ However, the varied effect of different fatty acids on the lipid components is well established, ${ }^{36}$ and the present study did not measure the intake of saturated, monounsaturated and polyunsaturated fatty acids during the fasting month.

Summers in Ajman are extremely hot and the extreme heat and humidity during the study made it very difficult to spend time outdoors for the patients exercising. Interview results suggested that physical activity was considered as moderate and was restricted to housework and walking; however, additional physical activity was induced due to "Taraouih" prayers which involve long periods of standing 1.5-2 hours after breaking the fast. These findings are in accordance to the EPIDIAR study which was a population based study in 13 countries. ${ }^{5}$ The improvement in the body compositions has been reported during the Ramadan fasting attributed to the 'Taraouih' prayers. ${ }^{37}$ We cannot rule out that this increased physical activity could in part have affected body weight and metabolism.

A limitation of the study was to find a control group, as it was not possible to find Emiratis with MS who did not fast 
during Ramadan. Our sample size of 19 was inadequate for subset analyses of the differential effects of Ramadan on gender, age group, ethnicity and other population differences.

\section{Conclusion}

To the best of our knowledge, this is the first study that has examined the effects of fasting during Ramadan in Ajman, UAE, in patients with the MS. Energy intake did not differ from that reported prior to the initiation of Ramadan. Larger meals compensated for lower frequency of food ingestion during the intervals between fasting. A significant increase in fat intake and substantial inclusion of sweets in daily eating was reflected in raised glucose and $\mathrm{HbA}_{1 \mathrm{c}}$ levels but not evident in the lipid profile which did not change for the worse. Total body mass and waist circumference were reduced after Ramadan fasting. In some patients, the physical activity increased as a result of increased length of prayers.

As a dietary recommendation it could be advised to increase the vegetable and whole fruit consumption and limit fat and sweetened foods to improve the health benefits of Ramadan fasting. An additional 20-30 minutes of physical activity could improve the benefits of fasting on health.

\section{Acknowledgments}

Professor Lars Brudin, Kalmar, Sweden for assistance with statistical analyses. Cooperation of the patients selected for the study is thankfully acknowledged too.

\section{Disclosure}

The authors report no conflicts of interest in this work.

\section{References}

1. Shariatpanahi ZV, Shariatpanahi MV, Shahbazi S, Hossaini A, Abadi A. Effect of Ramadan fasting on some indices of insulin resistance and components of the metabolic syndrome in healthy male adults. British Journal of Nutrition. 2008;100(1):147-151.

2. El Ati J, Beji C, Danguir J. Increased fat oxidation during Ramadan fasting in healthy women: an adaptive mechanism for body weight maintenance. Am J Clin Nutr. 1995;62:302-307.

3. Frost G, Pirani S. Meal frequency and nutritional intake during Ramadan: a pilot study. Hum Nutr Appl Nutr. 1987;4iA:47-50.

4. Khaled BM, Belbraouet S. Ramadan Fasting Diet Entailed a Lipid Metabolic Disorder among Type 2 Diabetic Obese Women. American Journal of Applied Sciences. 2009;6(3):471-477.

5. Salti I, Binard E, Detournay B, Bianchi-Biscay M, Le Brigand C, Voinet $\mathrm{C}$, et al. A population-based study of diabetes and its characteristics during the fasting month of Ramadan in 13 countries: Results of the epidemiology of diabetes and Ramadan 1422/2001 (EPIDIAR) study. Diabetes Care. 2004;27:2306-2311.

6. Benaji B, Mounib N, Roky R, et al. Diabetes and Ramadan. Review of the literature. Diabetes Research and Clinical Practice. 2006;73: 117-125.

7. Trepanowski JF, Bloomer RJ. The impact of religious fasting on human health. Nutrition Journal. 2010;9:57:2-9.
8. Musaiger AO, Miladi SS, eds. Food Consumption Patterns and Dietary Habits in the Arab Countries of the Gulf. Cairo: FNE/RNE; 1995.

9. Malik M, Razig SA. The prevalence of the metabolic syndrome among the multiethnic population of the United Arab Emirates: a report of a national survey. Metab Syndr Relat Disord. Sep 2008;6(3): $177-186$.

10. Sierra-Johnson, et al. Eating Meals Irregularly. A Novel Environmental Risk Factor for the Metabolic Syndrome. Obesity. 2008;16(6):1302.

11. Wannamethee SG, Shaper AG, Lennon L, Morris RW. Metabolic syndrome vs framingham risk score for prediction of coronary heart disease, stroke, and type 2 diabetes mellitus. Arch Intern Med. 2005; 165:2644-2650.

12. Manson JE, Skerrett PJ, Greenland P, VanItallie TB. The escalating pandemics of obesity and sedentary lifestyle. A call to action of clinicians. Arch Intern Med. 2004;164:249-258.

13. Esposito K, Marfella R, Ciotola M, et al. Effect of a Mediterranean-style diet on endothelial dysfunction and markers of vascular inflammation in the metabolic syndrome: a randomized trial. JAMA. 2004;292: 1440-1446.

14. Klein, S, Sheard NF, Pi-Sunyer X, et al. Weight management through lifestyle modification in the prevention and management of type 2 Diabetes: Rationale and strategies. A statement of the American diabetes association, the north American association for the study of obesity and the American Society for Clinical Nutrition. Diabetes Care. 2004;27: 2067-2073.

15. Bureau of Democracy, Human Rights, and Labor. United Arab Emirates international religious freedom report 2010 [report on the Internet]. 2010 [updated November 17, 2010; cited January 12, 2011]. Available from: http://www.state.gov/g/drl/rls/irf/2010/148850.htm. Accessed October 17, 2011.

16. http://www.idf.org/webdata/docs/IDF_Meta_def_final.pdf. (retrieved January 5,2011 ).

17. Cunningham JJ. Body composition as a determinant of energy expenditure: a synthetic review and a proposed general prediction equation. Am J Clin Nutr. 1991;54(6):9639.

18. National Health and Nutrition Examination Survey (NHANES) Anthropometry Procedures Manual, Jan 2007. http://www.cdc.gov/nchs/data/ nhanes/nhanes_07_08/manual_an.pdf. (retrieved April 5, 2011).

19. Stubbs RJ, Hughes DA, Johnstone AM, et al. The use of visual analogue scales to assess motivation to eat in human subjects: a review of their reliability and validity with an evaluation of new hand-held computerized systems for temporal tracking of appetite ratings. Br J Nutr. 2000; $84: 405-415$.

20. The fifth international conference on dietary assessment methods expanding the horizon: dietary assessment in a multicultural world. January 26-29, 2003 Chiang Rai, Thailand. http://www.icdam.org/ Abtract_ICDAM5.pdf. (retrieved June 15, 2011).

21. USDA National Nutrient Database for Standard Reference, www.nal usda.gov/fnic/foodcomp/Data/HG72/hg72_2002.pdf. (retrieved April 5, 2011).

22. Cobas 6000 analyzer series. Operator's Manual, version 4.0.2009, Germany.

23. Wallace TM, Levy JC, Matthews DR. Use and abuse of HOMA modeling. Diabetes Care. 2004;27(6):1487-1495.

24. Nelson W, Cadotte L, Halberg F. Circardian timings of single daily meal affects survival of mice. Proc Soc Exp Biol Med. 1973;144: 766-769.

25. Bogdan A, Bouchared B, Touitou Y. Ramadan fasting alters endocrine and neuroendocrine cicardian patterns. Meal-time as a synchronizer in humans? Life Sci. 2001;68:1607-1615.

26. Kassab S, Abdul-Ghaffar T, Nagalla DS, Sachdev U, Nayar U. Interactions between leptin, neuropeptide-Y and insulin with chronic diurnal fasting during Ramadan. Ann Saudi Med. 2004;24:345-349.

27. Wissam HI, Hosam MH, Amjad HJ, Samer AAB. Effect of Ramadan fasting on markers of oxidative stress and serum biochemical markers of cellular damage in healthy subjects. Ann Nutr Metab. 2008;53: $175-181$. 
28. Lamri-Senhadji MY, El Kebir B, Belleville J, Bouchenak M. Assessment of dietary consumption and time-course of changes in serum lipids and lipoproteins before, during and after Ramadan in young Algerian adults. Singapore Med J. 2009;50(3):288-294.

29. Saleh SA, Elsharouni SA, Cherian B, Mourou. Effects of Ramadan fasting on waist circumference, blood pressure, lipid profile, and blood sugar on a sample of healthy. Kuwaiti Men and Women. Mal J Nutr. 2005;11(2):143-150.

30. Richelsen B, Pedersen SB. Associations between different anthropometric measurements of fatness and metabolic risk parameters in non-obese, healthy, middle-aged men. Int J Obes Relat Metab Disord. 1995;19L:169-174.

31. Bonnet F, Ducluzeau PH, Gastaldelli A, et al; RISC Study Group. Liver enzymes are associated with hepatic insulin resistance, insulin secretion, and glucagon concentration in healthy men and women. Diabetes. Jun 2011;60(6):1660-1667.

32. Wallace TM, Utzschneider KM, Tong J, et al. Relationship of liver enzymes to insulin sensitivity and intra-abdominal fat. Diabetes Care. Oct 2007;30(10):2673-2678.
33. American Diabetes Association. Standards of Medical Care in Diabetes - 2008. Diabetes Care. 2008;31:5-11.

34. Franz MJ, Bantle JP, Beebe CA, Brunzell JD, Chiasson JL, Garg A, et al. Evidence based nutrition principles and recommendations for the treatment and prevention of diabetes and related complications (Technical Review). Diabetes Care. 2002;25:148-198.

35. Khaled BM, Belbraouet S. Effect of Ramadan fasting on anthropometric parameters and food consumption in 276 type 2 diabetic obese women. Int J Diabetes Dev Ctries. Apr 2009;29(2):62-68.

36. Gardner CD, Kraemer HC. Monounsaturated Versus Polyunsaturated Dietary Fat and Serum Lipids: A Meta-analysis. Arteriosclerosis, Thrombosis, and Vascular Biology. 1995;15: 1917-1927.

37. Mohktar MS, Ibrahim F. Assessment of Salat Taraweeh and Fasting Effect on Body Composition. 4th Kuala Lumpur International Conference on Biomedical Engineering 2008 IFMBE Proceedings, 2008;21 Part 3, Part 4:133-136.

\section{Publish your work in this journal}

Diabetes, Metabolic Syndrome and Obesity: Targets and Therapy is an international, peer-reviewed open-access journal committed to the rapid publication of the latest laboratory and clinical findings in the fields of diabetes, metabolic syndrome and obesity research. Original research, review, case reports, hypothesis formation, expert opinion and commentaries are all considered for publication. The manuscript management system is completely online and includes a very quick and fair peer-review system, which is all easy to use. Visit http://www.dovepress.com/testimonials.php to read real quotes from published authors.

Submit your manuscript here: http://www.dovepress.com/diabetes-metabolic-syndrome-and-obesity-targets-and-therapy-journal 